\title{
Effect of fat source differing in fatty acid profile on metabolic parameters, fertilization, and embryo quality in high-producing dairy cows
}

\author{
R. L. A. Cerri, ${ }^{*} \dagger$ S. O. Juchem, ${ }^{*}$ R. C. Chebel, ${ }^{*}$ H. M. Rutigliano, ${ }^{*}$ R. G. S. Bruno, ${ }^{*}$ K. N. Galvão, ${ }^{*}$ \\ W. W. Thatcher, $\dagger$ and J. E. P. Santos ${ }^{*} \dagger^{1}$ \\ *School of Veterinary Medicine, University of California-Davis, Tulare 93274 \\ †Department of Animal Sciences, University of Florida, Gainesville 32611
}

\begin{abstract}
The objectives were to evaluate the effects of source of fatty acids (FA) on embryo quality of dairy cows. A total of 154 Holstein cows were assigned randomly to 1 of 2 sources of FA supplemented at $2 \%$ of the dietary dry matter as calcium salts of either palm oil (PO) or linoleic and trans-octadecenoic acids (LTFA) from $25 \mathrm{~d}$ prepartum to $80 \mathrm{~d}$ in milk (DIM). Cows were presynchronized beginning at $30 \pm 3$ DIM and then subjected to the Ovsynch protocol beginning on $\mathrm{d}$ $39 \pm 3$ postpartum. Timed artificial insemination was performed $12 \mathrm{~h}$ after the final GnRH of the Ovsynch protocol with semen from a single sire of proven fertility. The uteri of cows were nonsurgically flushed at 5 $\mathrm{d}$ after artificial insemination for collection of embryosoocytes. Ovaries were examined by ultrasonography throughout the synchronization protocol. Blood was sampled and plasma was analyzed for concentrations of metabolites and hormones. The body condition score and yields of milk and milk components were measured throughout the first 90 DIM. Treatment did not affect concentrations of nonesterified FA, $\beta$-hydroxybutyrate, glucose, and progesterone in plasma. Body condition was similar between treatments. Milk production was similar between treatments, but concentrations of fat in milk and yields of fat and 3.5\% fat-corrected milk decreased in cows fed LTFA, whereas concentration of true protein increased. Source of dietary FA did not influence ovulatory responses, diameter of the ovulatory follicle, and diameter of the corpus luteum during synchronization. Embryo-oocyte recovery relative to the number of corpora lutea did not differ between treatments. Fertilization tended to increase in cows fed LTFA compared with cows fed PO. Feeding LTFA improved the proportion of excellent-, good-, and fairquality embryos, and embryos from cows fed LTFA had a greater number of blastomeres than embryos from
\end{abstract}

Received August 8, 2008.

Accepted October 23, 2008.

${ }^{1}$ Corresponding author: jepsantos@ufl.edu cows fed PO. Feeding a more unsaturated source of FA improved fertilization and embryo development in lactating dairy cows, despite similar indicators of metabolic status.

Key words: dairy cow, embryo quality, fatty acid, reproduction

\section{INTRODUCTION}

Certain fatty acids (FA) have specific effects on different tissues, with potential benefits to the fertility of dairy cows. These benefits seem to be independent of the provision of calories and changes in the energy status of the cow (Staples et al., 1998; Santos et al., 2008b). Differential effects of specific FA on reproductive tissues have been demonstrated in vitro and in vivo on steroidogenesis (Wathes et al., 2007), metabolism of endometrial cells (Mattos et al., 2003, 2004), and embryo quality and development (Thangavelu et al., 2007; Santos et al., 2008b).

Linoleic acid (C18:2n-6) is an essential FA required for normal reproductive function in mammals (Burr and Burr, 1930). Recently, high-producing dairy cows fed a supplemental fat enriched with linoleic acid and a blend of trans-octadecenoic FA (LTFA) had increased pregnancy at 27 and $41 \mathrm{~d}$ after AI (Juchem et al., 2008); however, the causes for such improvement were not clearly determined. As the precursor for endogenous synthesis of arachidonic acid (C20:4n-6), linoleic acid could increase the incorporation of arachidonic acid in membrane phospholipids of endometrial cells and, consequently, $\mathrm{PGF}_{2 \alpha}$ synthesis (Mattos et al., 2003), with the latter playing an important role postpartum in uterine involution (Kindahl et al., 1992). Enhancing uterine health, even past the immediate postpartum period, has the potential to improve the fertility of dairy cows, as evidenced by better fertilization (Cerri et al., 2009a) and pregnancy (Rutigliano et al., 2008), in cows not diagnosed with subclinical endometritis after 30 DIM. Furthermore, evidence of a direct beneficial effect of linoleic acid during early embryo development has been observed in more developed human embryos that 
incorporated more linoleic acid compared with their undeveloped counterparts (Haggarty et al., 2006). An increased number of blastomeres was observed when superstimulated embryo donor cows were fed diets enriched with either linoleic or $\alpha$-linolenic acid (C18:3n-3) compared with a saturated source of FA (Thangavelu et al., 2007). Therefore, it is plausible to speculate that increased intake of linoleic acid could affect the FA composition of reproductive tissues and, in turn, improve fertilization rate and embryonic development. This might explain the improved pregnancy per AI observed in lactating dairy cows fed a calcium salt of LTFA (Juchem et al., 2008).

Monoenoic FA containing a single double bond in the trans configuration, such as trans-octadecenoic FA, have distinct biological effects and can inhibit synthesis of fat in the mammary gland (Piperova et al., 2004), although their effects on lipogenesis seem to be less dramatic than those of specific conjugated linoleic acids. A concept that has been evaluated is the potential for FA that suppress milk fat synthesis to alleviate the negative energy balance and improve reproduction (CastañedaGutiérrez et al., 2007; Juchem et al., 2008). However, suppressing milk fat synthesis by feeding trans FA does not seem to improve metabolism and energy balance to justify the benefits to reproduction (Juchem et al., 2004, 2008; Castañeda-Gutiérrez et al., 2007). Nevertheless, if trans-octadecenoic FA fed in early lactation affect plasma concentrations of NEFA and BHBA, it is possible that they could decrease the negative effects associated with excessive concentrations of these metabolites on the developmental capacity of oocytes (Leroy et al., 2005) and pregnancy rates (Walsh et al., 2007).

The objectives of the present study were to determine the effects of feeding a rumen-inert fat enriched with LTFA during late gestation and early lactation on indicators of metabolic status, fertilization rate, and embryo quality in dairy cows. It was hypothesized that supplementation with the more unsaturated LTFA would benefit the metabolic status of the cow by decreasing milk fat synthesis and reducing concentrations of NEFA and BHBA postpartum. Furthermore, it was hypothesized that providing a diet enriched with LTFA would improve the fertilization and embryo quality of nonsuperstimulated dairy cows.

\section{MATERIALS AND METHODS}

\section{Animals and Housing}

The University of California-Davis Institutional Animal Care and Use Committee approved all procedures involving cows in this study. A total of 154 lactating
Holstein dairy cows (105 multiparous and 49 primiparous) were randomly assigned to initiate 1 of 2 treatments beginning at $25 \mathrm{~d}$ prepartum.

\section{Treatment Diets}

All cows were fed the same diet as a TMR once daily prepartum and twice daily postpartum, except for the supplemental fat. Diets met or exceeded the dietary requirements (NRC, 2001) for a nonlactating cow of 670 $\mathrm{kg}$ consuming $12 \mathrm{~kg}$ of $\mathrm{DM}$ during the last trimester of pregnancy and for a lactating cow weighing $630 \mathrm{~kg}$ consuming $24 \mathrm{~kg}$ of DM and producing $45 \mathrm{~kg}$ of milk containing $3.5 \%$ fat and $3.1 \%$ true protein in the first $70 \mathrm{~d}$ of lactation. Diets were formulated by using the CPM-Dairy cattle ration analyzer (Cornell-Penn-Miner version 3.0.8; Miner Institute, Chazy, NY). Amounts offered and refused were measured daily.

Diets differed between treatments only by the nature of the FA profile contained in the supplemental fat offered to the cows. Supplemental fat in the form of calcium salt was offered from $\mathrm{d}-25$ relative to calving until 70 DIM, which was expected to result in an intake of supplemental fat of approximately 200 and $400 \mathrm{~g} / \mathrm{d}$ for the pre- and postpartum periods, respectively. Cows were fed a calcium salt of palm oil (PO; $2 \%$ of dietary DM; EnerG-II, Virtus Nutrition LLC, Fairlawn, OH) containing mostly saturated (palmitic acid: C16:0) and monounsaturated FA (oleic acid: C18:1 cis-9), or a calcium salt containing mostly linoleic acid (C18:2 cis-9, cis-12) and a blend of trans-octadecenoic (C18:1 trans) FA (LTFA; $2 \%$ of dietary DM; EnerG-I Transition Formula, Virtus Nutrition LLC). A total of 76 cows in the PO group (25 primiparous and 51 multiparous) and 78 cows in the LTFA group (24 primiparous and 54 multiparous) were enrolled in the study. Cows were housed in 2 pre- and 2 postpartum pens/treatment, and all diets were rotated through all pre- and postpartum pens. Prepartum pens housed 38 to 44 cows any given day, and postpartum pens housed 85 to 90 cows any given day.

Pre- and postpartum diets were sampled weekly from the manger in each pen and then composited for 2-mo periods. Every batch of calcium salts was sampled, and a composite sample was analyzed for FA profile by GC (DePeters et al., 2001). Chemical composition of the experimental diets and FA profile of the calcium salts are shown in Table 1. Amounts of diets offered and refused were measured daily.

\section{BCS, Milk Yield, and Milk Components}

The BCS (Ferguson et al., 1994) of all cows was determined by the same person on $\mathrm{d}-25,1,40$, and 70 
Table 1. Chemical composition of experimental $\operatorname{diets}^{1}$ (mean $\pm \mathrm{SD}$ ), and fatty acid profile of the supplemental fat sources

\begin{tabular}{|c|c|c|c|c|}
\hline Item & \multicolumn{2}{|c|}{ Prepartum diet } & \multicolumn{2}{|c|}{ Postpartum diet } \\
\hline $\begin{array}{l}\mathrm{NE}_{\mathrm{L}},{ }^{2} \mathrm{Mcal} / \mathrm{kg} \text { of } \mathrm{DM} \\
\mathrm{CP}, \% \\
\text { Fat, } \% \\
\mathrm{NDF}, \%\end{array}$ & $\begin{aligned} 1.73 & \pm 0.03 \\
12.0 & \pm 0.6 \\
4.4 & \pm 0.3 \\
32.6 & \pm 2.5\end{aligned}$ & $\begin{aligned} 1.76 & \pm 0.02 \\
11.7 & \pm 0.7 \\
5.2 & \pm 0.4 \\
31.5 & \pm 1.5\end{aligned}$ & $\begin{aligned} 1.67 & \pm 0.01 \\
16.9 & \pm 0.3 \\
5.2 & \pm 0.4 \\
30.1 & \pm 2.4\end{aligned}$ & $\begin{aligned} 1.70 & \pm 0.01 \\
17.2 & \pm 0.8 \\
5.2 & \pm 0.5 \\
31.5 & \pm 0.5\end{aligned}$ \\
\hline $\begin{array}{l}\text { C16:0 } \\
\text { C18:0 } \\
\text { C18:1, total cis } \\
\text { C18:1, total trans } \\
\text { C18:2n-6 } \\
\text { C18:2 trans-10, cis-12 } \\
\text { C18:3n-3 } \\
\text { C20:5n-3 } \\
\text { C22:6n-3 }\end{array}$ & & & & \\
\hline
\end{tabular}

${ }^{1} \mathrm{PO}=$ calcium salt of palm oil; LTFA = calcium salt of linoleic and trans-octadecenoic acids.

${ }^{2}$ Calculated according to NRC (2001).

relative to calving. Milk yields were measured weekly during the first 10 wk of lactation by the DHIA laboratory in Hanford, California. Milk samples were collected once weekly for the morning and afternoon milkings and analyzed for concentrations of fat, true protein, and SCC (Foss 303 Milk-O-Scan; Foss Foods Inc., Eden Prairie, MN).

\section{Blood Sampling and Analysis of Progesterone, NEFA, BHBA, and Glucose}

Approximately $7 \mathrm{~mL}$ of blood was sampled from the coccygeal vein or artery into evacuated tubes containing $17.55 \mathrm{mg}$ of $\mathrm{K}_{2}$ EDTA (Vacutainer, Becton Dickinson, Franklin Lakes, NJ). Plasma was obtained from blood after centrifugation at $3,000 \times g$ for $15 \mathrm{~min}$ in a refrigerated centrifuge at $5^{\circ} \mathrm{C}$. Plasma was then stored at $-25^{\circ} \mathrm{C}$ until further analyses for concentrations of progesterone, NEFA, BHBA, and glucose.

Blood samples for progesterone analysis were collected at the moment of $\mathrm{PGF}_{2 \alpha}$ injection of the presynchronization and at every injection of the Ovsynch protocol to evaluate the ovarian response to the hormonal treatments. Additional samples were collected at d 3 and 5 after AI to determine the changes in plasma progesterone concentration until the day of embryooocyte collection. Plasma progesterone was analyzed by a validated ELISA (Cerri et al., 2004). The intra- and interassay CV in the study assays were, respectively, 4.9 and $7.3 \%$. Individual samples with CV $>15 \%$ or microplates with interassay CV $>15 \%$ were reanalyzed.

Blood was sampled at $-22,-14,-7,1,6,13$, and $27 \mathrm{~d}$ relative to calving and analyzed for concentra- tions of NEFA, BHBA, and glucose. Plasma NEFA concentrations were determined by using a colorimetric kit (NEFA-C, Wako Chemicals GmbH, Neuss, Germany). Concentrations of BHBA were determined by a colorimetric kit (Randox Laboratories Ltd., Crumlin, Ireland) following a modified kinetic protocol for a microplate reader. Glucose concentrations in plasma were analyzed based on the glucose oxidase reaction by using a biochemical analyzer (YSI 2700-S BioChem, Yellow Springs Instrument Co. Inc., Ohio OH).

\section{Ovulation Synchronization Protocol and AI}

Cows in both treatments were subjected to an identical reproductive protocol for timed AI (Figure 1). The estrous cycles of cows were presynchronized beginning at $30 \pm 3 \mathrm{DIM}$, and the protocol consisted of an injection of $100 \mu \mathrm{g}$ of GnRH (gonadorelin diacetate tetrahydrate; Cystorelin, Merial Ltd., Iselin, NJ) and the placement of a controlled internal drug-releasing insert containing $1.38 \mathrm{~g}$ of progesterone (CIDR; EAZI-Breed, Pfizer Animal Health, New York, NY). An injection of $25 \mathrm{mg}$ of $\mathrm{PGF}_{2 \alpha}$ (dinoprost tromethamine; Lutalyse Sterile Solution, Pfizer Animal Health) was given $7 \mathrm{~d}$ later concomitantly with the removal of the controlled internal drug-releasing insert. The Ovsynch protocol (Pursley et al., 1995) began $2 \mathrm{~d}$ after the end of presynchronization and consisted of an injection of $100 \mu \mathrm{g}$ of $\mathrm{GnRH}$, followed by $25 \mathrm{mg}$ of $\mathrm{PGF}_{2 \alpha} 7 \mathrm{~d}$ later and a final injection of $\mathrm{GnRH}$ given $48 \mathrm{~h}$ after the $\mathrm{PGF}_{2 \alpha}$. Cows were artificially inseminated $12 \mathrm{~h}$ after the last injection of GnRH of the Ovsynch protocol. The same person artificially inseminated all cows in the study. 


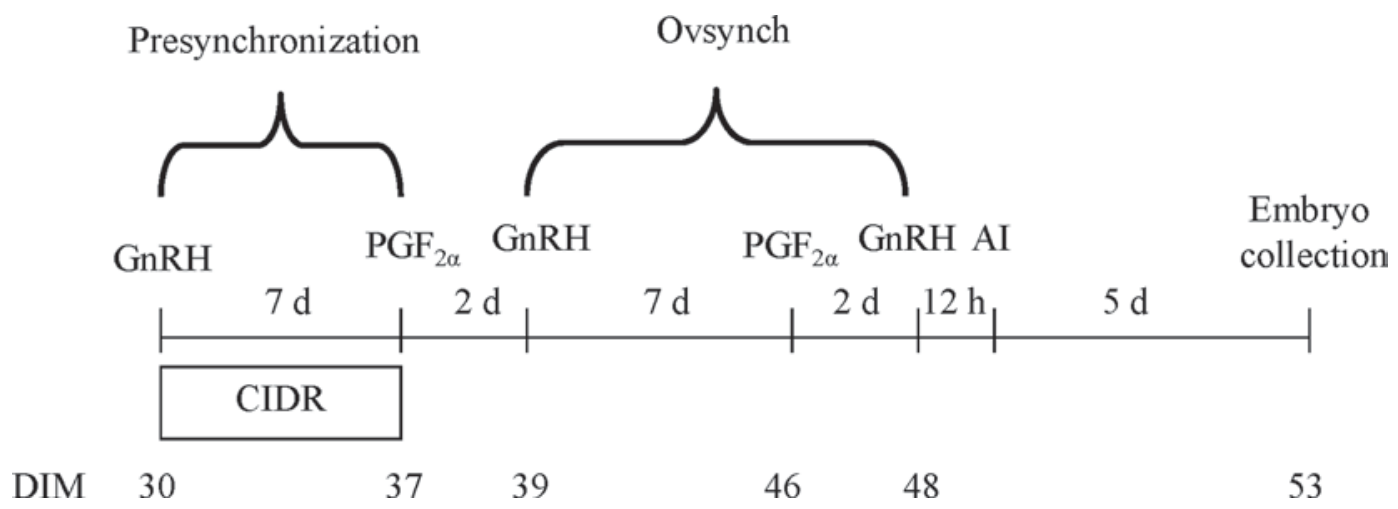

Figure 1. Diagram of the reproductive protocol used to synchronize ovulation in all cows. CIDR = controlled internal drug-releasing insert containing $1.38 \mathrm{~g}$ of progesterone.

Semen from a single proven sire previously tested for fertility from field inseminations in lactating cows was used in both treatments.

\section{Ultrasound Evaluation of the Ovarian Structures}

Cows had their ovaries examined by ultrasound (7.5$\mathrm{MHz}$ transrectal linear probe; Sonovet 2000, Alliance Medical, Bedford Hills, NY) for determination of ovarian structures and response to hormonal treatments. Maps of the ovaries were drawn for each individual cow, and the size and position of follicles $\geq 5 \mathrm{~mm}$ in diameter and corpora lutea $(\mathbf{C L})$ were recorded. Ultrasonographic images were taken immediately before the injections of GnRH and $\mathrm{PGF}_{2 \alpha}$ of the presynchronization to determine cyclic status. Cows with a visible CL in at least 1 of the 2 ultrasound examinations were considered cyclic, and cows without a CL in both examinations were considered anovular. Ovaries were then scanned at the time of each injection of the Ovsynch protocol and again $48 \mathrm{~h}$ after each GnRH injection to determine ovulation. An additional ultrasound evaluation was performed at the moment of embryo-oocyte collection to determine the diameter of the CL. Occurrence of ovulation within $48 \mathrm{~h}$ after each $\mathrm{GnRH}$ injection was characterized by the disappearance of a previously recorded follicle $\geq 10$ $\mathrm{mm}$ in diameter.

\section{Embryo-Oocyte Collection and Evaluation}

Cows were flushed on d 5 after AI by a transcervical procedure using a silicone Foley catheter (18 French, $30 \mathrm{~mL}, 56 \mathrm{~cm}$ ). The balloon of the Foley catheter was placed approximately $3 \mathrm{~cm}$ past the external intercornual ligament of the uterine horn ipsilateral to the CL. Approximately $300 \mathrm{~mL}$ of a flushing solution (ViGro complete flush solution, Bioniche Life Sciences Inc., Belleville, Ontario, Canada) was used in each uterine horn in 20 cycles of infusion/recovery of $15 \mathrm{~mL}$ of solution. Recovered embryos-oocytes were then evaluated for fertilization and grade quality $(1=$ excellent and good, 2 = fair, $3=$ poor, and $4=$ degenerated) according to the guidelines of the International Embryo Transfer Society (1998). Embryos were stained with 5 $\mu \mathrm{g} / \mathrm{mL}$ of propidium iodide (Sigma, St. Louis, MO) to determine the number of nonviable blastomeres and then with $5 \mu \mathrm{g} / \mathrm{mL}$ of Hoechst 33342 stain (Molecular Probes Inc., Eugene, OR) to determine the number of accessory spermatozoa by epifluorescence microscopy (365 nm excitation, $>400 \mathrm{~nm}$ emission). The zona pellucida was then dissolved with a solution of $0.02 \mathrm{~N}$ $\mathrm{HCl}$ in $0.1 \%$ Tween-20 (Sigma). The embryo was again stained with $5 \mu \mathrm{g} / \mathrm{mL}$ of Hoechst 33342 stain, and the blastomeres were spread on a glass slide and counted by epifluorescence microscopy.

\section{Experimental Design and Statistical Analyses}

The experimental design was a randomized complete block design. Cows were blocked according to parity (first vs. greater than first lactation) and BCS (Ferguson et al., 1994) at enrollment and, within each block, were randomly assigned to 1 of the 2 treatments.

Binomial data were evaluated by logistic regression using the LOGISTIC procedure of SAS/STAT (SAS Inst. Inc., Cary, NC). The model included the effects of treatment, parity, average BCS postpartum, and BCS change between calving and 70 DIM. Count data, such as number of accessory sperm and number of total blastomeres, were analyzed by the GENMOD procedure using a Poisson distribution with correction for overdispersion of data (SAS/STAT, SAS Inst. Inc.). The model included the effects of treatment, parity, average BCS postpartum, and BCS change between calving and 70 DIM. Median and mean values were obtained. 
Blood metabolites (NEFA, BHBA, and glucose) and progesterone concentrations, as well as milk production and milk components were analyzed by ANOVA for repeated measures using PROC MIXED of the SAS/ STAT program (SAS Inst. Inc.). The covariance structure with the smallest Akaike's information criterion was used for the measurements used in the PROC MIXED model. The model included the effects of treatment, day of measurement, interaction of treatment $x$ day of measurement, parity, and average BCS postpartum, with cow nested within treatment as the random error. For progesterone, analyses were performed separately for samples collected before and after $\mathrm{PGF}_{2 \alpha}$ injections during the synchronization treatments.

Simple and partial correlations were performed to assess the associations between NEFA, BHBA, and glucose concentrations with outcomes of the collected embryos-oocytes. Correlation analysis using Pearson correlation was performed with PROC CORR of the SAS/STAT program (SAS Inst. Inc.). A multivariate ANOVA was used to evaluate the partial correlations by PROC GLM (SAS/STAT, SAS Inst. Inc.). Treatment differences with $P \leq 0.05$ were considered significant, and from $0.05<P \leq 0.10$ were designated as a tendency.

\section{RESULTS}

As expected, the chemical compositions of the preand postpartum diets were similar (Table 1), but the FA profile of the supplemental fat sources differed markedly. The PO contained $50 \%$ of its FA as palmitic and oleic acids, whereas the LTFA contained more than $75 \%$ of its FA as mono- and polyunsaturated FA.

Cows received the prepartum diets for a similar period of time, $25.6 \pm 0.6$ and $25.5 \pm 0.6 \mathrm{~d}$ for $\mathrm{PO}$ and LTFA, respectively. The mean $( \pm \mathrm{SD})$ and median lactation number did not differ $(P>0.54)$ between treatments and were $2.36 \pm 1.34$ and 2.00 , respectively. Dry matter intake did not differ for PO and LTFA in the prepartum $(12.2 \pm 0.4$ and $12.6 \pm 0.4 \mathrm{~kg} / \mathrm{d} ; P=$ $0.68)$ and postpartum $(23.2 \pm 0.5$ and $22.8 \pm 0.6 \mathrm{~kg} / \mathrm{d}$; $P=0.32$ ) periods.

\section{BCS}

The mean BCS collected throughout the study (Figure 2) did not differ between treatments. There was an effect $(P<0.001)$ of day as cows lost BCS from calving to 40 DIM, but no interaction was observed between treatment and day of BCS evaluation. During the study period, multiparous cows had a smaller $(P<0.001)$ mean BCS than did primiparous cows $(3.23 \pm 0.01$ vs. $3.55 \pm 0.02)$.

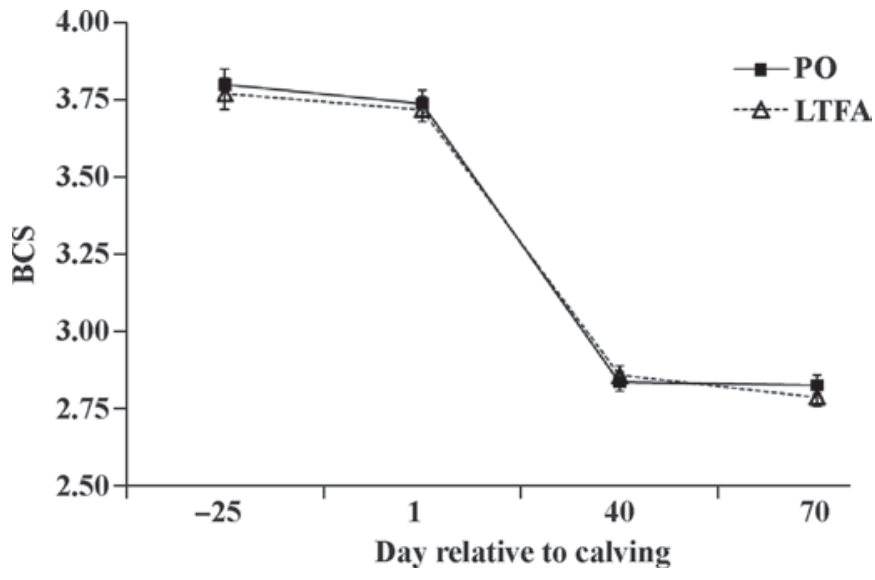

Figure 2. Body condition score of cows fed calcium salts of palm oil (PO) or linoleic and trans-octadecenoic acids (LTFA). Effects of treatment $(P=0.22)$, day relative to calving $(P<0.001)$, and the interaction between treatment and day relative to calving $(P=0.40)$.

\section{Plasma NEFA, BHBA, and Glucose}

Concentrations of NEFA and BHBA did not differ for cows fed PO or LTFA throughout the study (Figure 3). Similarly, no effect of treatment was observed for mean glucose concentration, but an interaction $(P=0.002)$ between treatment and day postpartum was observed, with a greater glucose concentration at $\mathrm{d} 1$ postpartum in cows fed PO than those fed LTFA $(74.1 \pm 1.35$ vs. $68.4 \pm 1.30 \mathrm{mg} / \mathrm{dL})$. In both treatments, concentration of NEFA increased $(P<0.001)$ sharply in the week before calving, but that of BHBA increased ( $P$ $<0.001)$ only after calving. Plasma NEFA and BHBA concentrations peaked at 6 and 13 DIM, respectively. Concentrations of glucose remained elevated until calving, followed by a steep decline $(P<0.001)$ in the first week postpartum, reaching a nadir at 13 DIM.

\section{Milk Yield and Components}

Average milk production during the first 10 wk of lactation (Table 2) was similar between PO and LTFA; however, $3.5 \%$ FCM was greater $(P=0.001)$ for cows fed PO than for cows fed LTFA because of the reduced $(P=0.001)$ fat content when cows were fed calcium salts containing trans $\mathrm{FA}$ and linoleic acid. The reduction in milk fat content with feeding LTFA resulted in a reduced $(P=0.001)$ fat yield when compared with cows fed PO. On the other hand, milk true protein concentration was less $(P=0.001)$ in cows fed PO than in cows fed LTFA, although milk true protein yield did not differ between treatments. The SCC did not differ between PO and LTFA. 

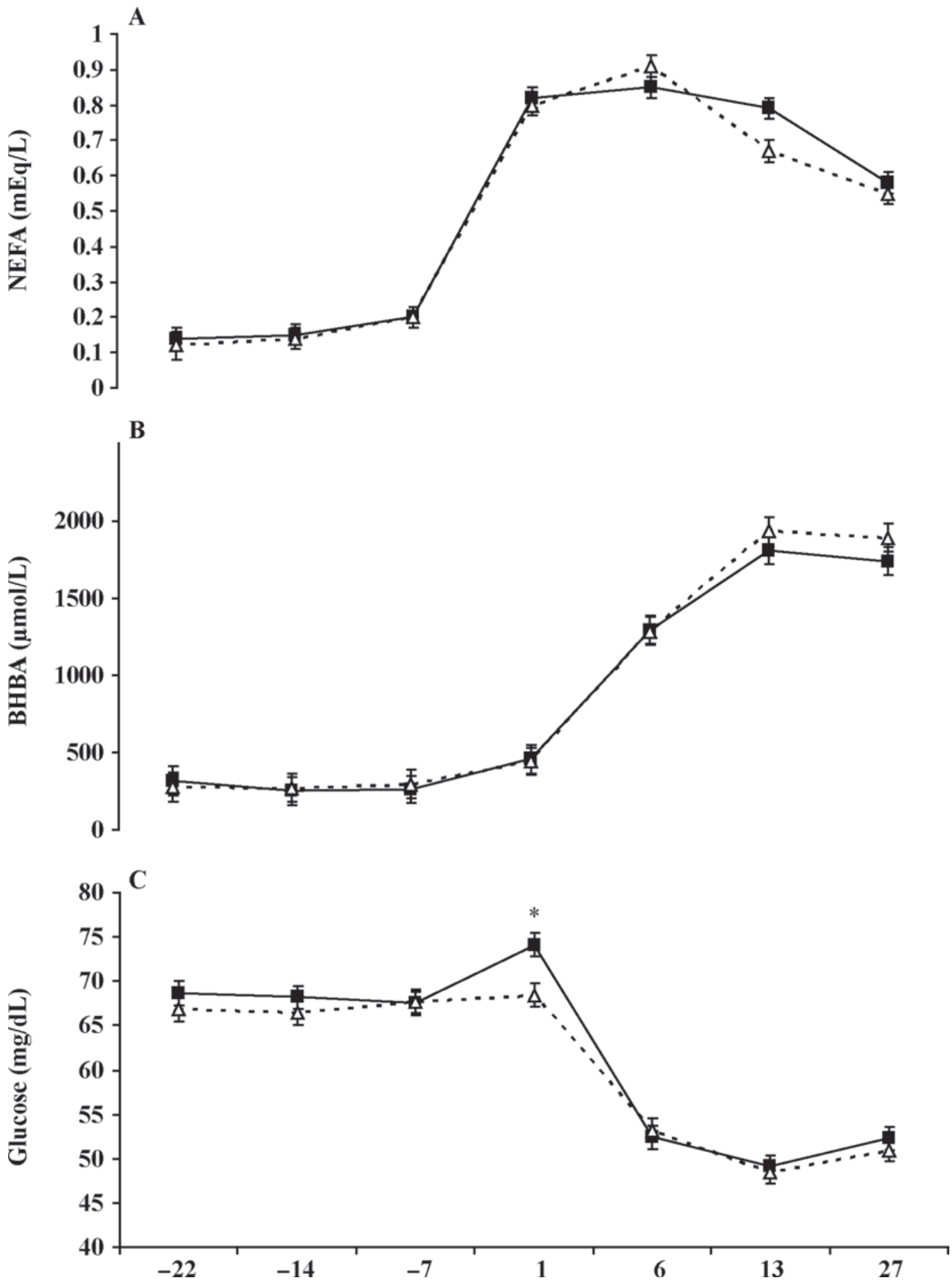

Figure 3. Plasma concentrations of NEFA (panel A), BHBA (panel B), and glucose (panel C) during the pre- and postpartum periods for cows fed calcium salts of palm oil (PO; - - - ) or linoleic and trans-octadecenoic acids (LTFA; -- $\triangle--)$. Plasma concentrations did not differ between PO and LTFA for NEFA $(P=0.80)$, BHBA $(P=0.58)$, and glucose $(P=0.20)$. There was an effect $(P<0.001)$ of day of sampling on concentrations of NEFA, BHBA, and glucose in plasma. There were no interactions between treatment and day for NEFA $(P=0.20)$ and BHBA $(P=0.23)$, but concentration of glucose was greater $\left({ }^{*} P=0.002\right)$ on $\mathrm{d} 1$ postpartum for cows fed PO compared with cows fed LTFA 
Table 2. Effect of source of dietary fatty acids on production and composition of milk in the first 10 wk of lactation

\begin{tabular}{lcccc}
\hline & \multicolumn{2}{c}{ Treatment $^{1}$} & & \\
\cline { 2 - 3 } Item & PO & LTFA & SEM & $P$-value \\
\hline Milk, kg/d & 38.6 & 38.2 & 0.64 & 0.63 \\
$\begin{array}{l}3.5 \% \mathrm{FCM}, \mathrm{kg} / \mathrm{d} \\
\text { Milk fat }\end{array}$ & 39.2 & 36.9 & 0.63 & 0.001 \\
$\quad \%$ & 3.63 & 3.37 & 0.03 & 0.001 \\
$\mathrm{~kg} / \mathrm{d}$ & 1.39 & 1.26 & 0.02 & 0.001 \\
Milk true protein & & & & \\
$\quad \%$ & 2.75 & 2.82 & 0.01 & 0.001 \\
$\mathrm{~kg} / \mathrm{d}$ & 1.06 & 1.08 & 0.02 & 0.51 \\
$\mathrm{SCC}, \times 10^{3} / \mathrm{mL}$ & 107.2 & 109.6 & 12.3 & 0.88 \\
\hline
\end{tabular}

${ }^{1} \mathrm{PO}=$ calcium salt of palm oil; LTFA = calcium salt of linoleic and trans-octadecenoic acids.

\section{Ovarian Structures, Responses to the Ovsynch Protocol, and Progesterone Concentration}

The effect of fat source on ovarian follicles and CL, and responses to hormonal treatments are depicted in Table 3. The prevalence of cyclic cows tended $(P$ $=0.06)$ to differ, and more cows fed PO were cyclic than cows fed LTFA. Ovulations to the first and second GnRH injections in the Ovsynch protocol, as well as CL regression after administration of $\mathrm{PGF}_{2 \alpha}$ were not different between treatments. Synchronization of ovulation, which included CL regression and ovulation within $48 \mathrm{~h}$ after the second $\mathrm{GnRH}$ of the Ovsynch protocol, was similar between treatments and averaged $83.1 \%$. Proportion of cows with double ovulation after the second GnRH of the Ovsynch protocol did not differ between the PO and LTFA groups when all cows or only ovulatory cows were considered. Diameter of the preovulatory follicle at the final $\mathrm{GnRH}$ of the Ovsynch protocol was similar between treatments and averaged
$18.3 \pm 0.4 \mathrm{~mm}$. Diameter of the CL at $5 \mathrm{~d}$ after AI, on the day of uterine flushing, also was similar between treatments and averaged $21.8 \pm 0.5 \mathrm{~mm}$.

Concentration of progesterone was greater $(P=0.02)$ for cows fed PO compared with cows fed LTFA at the time of $\mathrm{PGF}_{2 \alpha}$ injection $(3.6 \pm 0.1$ vs. $2.8 \pm 0.1 \mathrm{ng} / \mathrm{mL})$ before initiation of the Ovsynch protocol (Figure 4). The concentrations of progesterone at different times in the Ovsynch protocol, at AI, and in the $5 \mathrm{~d}$ after AI were did not differ between the PO and LTFA groups. After AI, progesterone increased $(P<0.001)$ in the first $5 \mathrm{~d}$, but no interaction between treatment and day after AI was detected.

\section{Embryo-Oocyte Evaluation}

The proportion of embryos-oocytes recovered on $\mathrm{d}$ 5 after AI relative to the number of CL was similar between treatments and averaged $52.5 \%$ (Table 4). Fertilization tended $(P=0.10)$ to be greater for cows fed LTFA than for those fed PO. Relative to embryosoocytes, cows fed LTFA were 3.2 times more likely $(P=0.02)$ to have embryos graded as 1 and 2 than cows fed PO. The proportion of degenerated embryos was similar between treatments, but when data from both unfertilized and degenerate embryos-oocytes were evaluated together, cows fed LTFA tended $(P=0.10)$ to have a smaller proportion of nonviable structures than cows fed PO.

Relative to embryos only, cows fed LTFA had a greater $(P=0.05)$ proportion of grades 1 and 2 embryos than cows fed PO, but the proportions of degenerated embryos did not differ between treatments (Table 4). The mean number of blastomeres differed $(P=0.01)$, and cows fed PO had fewer cells than cows fed LTFA; however, the median number of blastomeres

Table 3. Effect of source of dietary fatty acids on cyclic status and on ovarian responses to the Ovsynch protocol

\begin{tabular}{|c|c|c|c|c|c|}
\hline \multirow[b]{2}{*}{ Item } & \multicolumn{2}{|c|}{ Treatment, ${ }^{1} \%(\mathrm{n} / \mathrm{n})$} & \multirow[b]{2}{*}{$\mathrm{AOR}^{2}$} & \multirow[b]{2}{*}{$95 \% \mathrm{CI}^{3}$} & \multirow[b]{2}{*}{$P$-value } \\
\hline & $\mathrm{PO}$ & LTFA & & & \\
\hline Cyclic cows & $97.3(73 / 75)$ & $88.5(69 / 78)$ & 0.2 & $0.1-.0$ & 0.06 \\
\hline Ovulation to first $\mathrm{GnRH}^{4}$ & $83.0(63 / 76)$ & $84.6(66 / 78)$ & 1.2 & $0.5-2.9$ & 0.67 \\
\hline CL regression & $96.0(73 / 76)$ & $92.3(72 / 78)$ & 0.5 & $0.1-2.0$ & 0.33 \\
\hline Ovulation to second GnRH & $89.5(68 / 76)$ & $83.3(65 / 78)$ & 0.6 & $0.2-1.7$ & 0.37 \\
\hline Double - ovulatory cows & $19.1(13 / 68)$ & $20.0(13 / 65)$ & 1.2 & $0.5-2.9$ & 0.72 \\
\hline Double-all cows & $17.1(13 / 76)$ & $16.7(13 / 78)$ & 1.0 & $0.4-2.6$ & 0.90 \\
\hline Synchronization & $86.8(66 / 76)$ & $79.5(62 / 78)$ & 0.6 & $0.3-1.5$ & 0.32 \\
\hline Dominant follicle at AI, mm & $18.1 \pm 0.4$ & $18.5 \pm 0.4$ & - & - & 0.56 \\
\hline Corpus luteum diameter $5 \mathrm{~d}$ after AI, mm & $21.7 \pm 0.5$ & $21.8 \pm 0.5$ & - & - & 0.80 \\
\hline
\end{tabular}

${ }^{1} \mathrm{PO}=$ calcium salt of palm oil; LTFA $=$ calcium salt of linoleic and trans-octadecenoic acids

${ }^{2} \mathrm{AOR}=$ adjusted odds ratio. The PO treatment was used as the referent group.

${ }^{3} \mathrm{CI}=$ confidence interval.

${ }^{4}$ One LTFA was not evaluated for ovulation to the first GnRH because this cow missed the ultrasonographic examination of the ovaries on the day of the first GnRH of the Ovsynch protocol. 


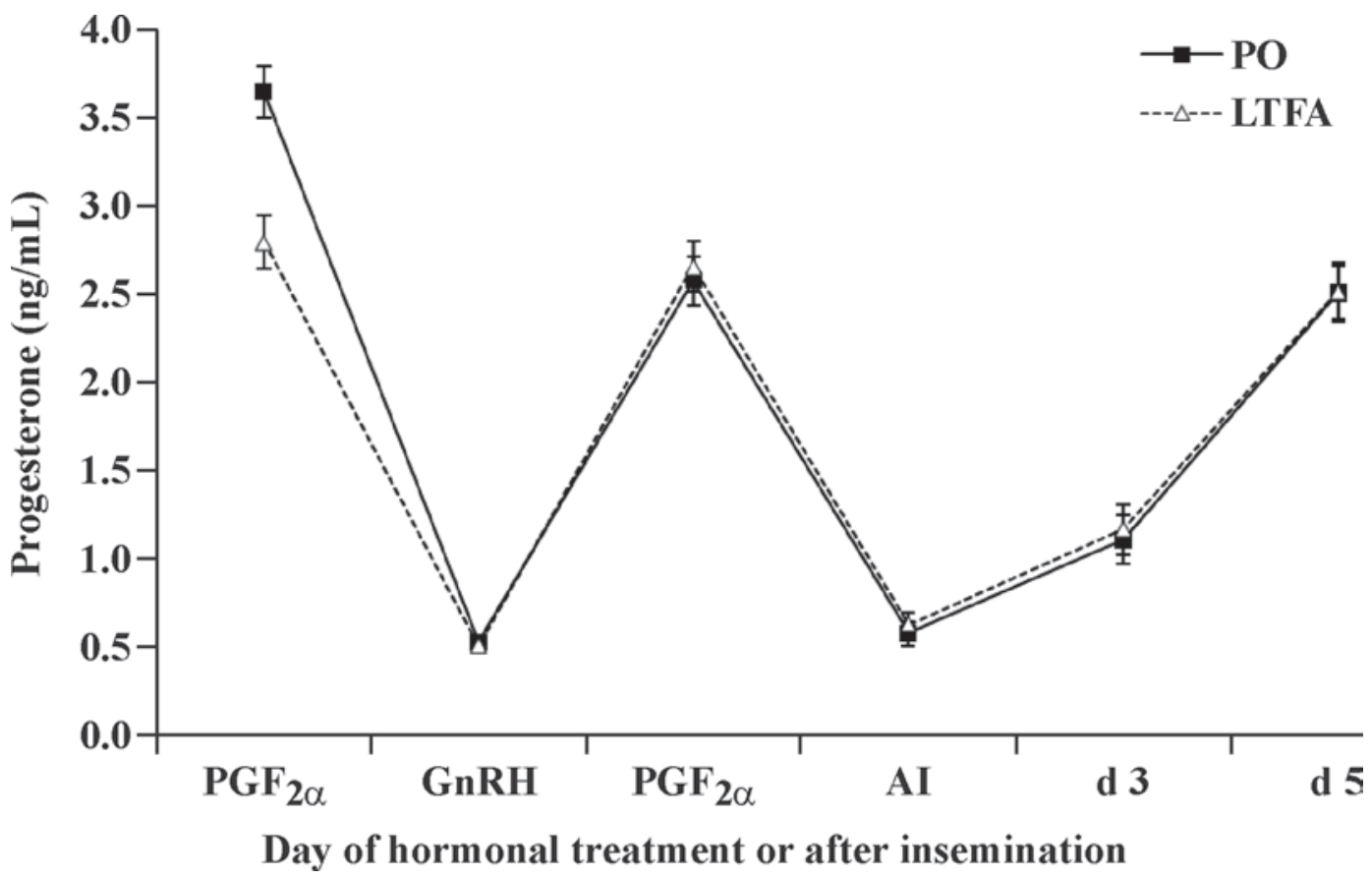

Figure 4. Concentrations of progesterone in plasma during the synchronization protocol in cows fed calcium salts of palm oil (PO) or linoleic and trans-octadecenoic acids (LTFA). Cows fed PO had greater $(* P=0.02)$ concentration of progesterone at the ${ }^{*} \mathrm{PF}_{2 \alpha}$ of the presynchronization. Progesterone concentrations were similar $(P>0.68)$ between treatments on the remaining days. After AI, concentrations of progesterone increased $(P<0.001)$, but no interaction $(P=0.28)$ between treatment and day after AI was detected.

and proportion of live blastomeres remained similar between treatments. The median number of accessory spermatozoa and embryos-oocytes with at least 1 accessory spermatozoon were similar between treatments, but the mean number was greater $(P<0.01)$ in the LTFA group compared with the PO group.
Although treatments influenced embryo quality, no relationships were observed between the proportion of embryos graded as 1 and 2 and mean concentrations of NEFA and BHBA during the pre- and postpartum periods or between NEFA and BHBA peak concentrations in the postpartum period. Simple and partial

Table 4. Effect of source of dietary fatty acids on recovery, fertilization, and quality responses of embryos-oocytes

\begin{tabular}{|c|c|c|c|c|c|}
\hline \multirow[b]{2}{*}{ Item } & \multicolumn{2}{|c|}{ Treatment, ${ }^{1} \%(\mathrm{n} / \mathrm{n})$} & \multirow[b]{2}{*}{$\mathrm{AOR}^{2}$} & \multirow[b]{2}{*}{$95 \% \mathrm{CI}^{3}$} & \multirow[b]{2}{*}{$P$-value } \\
\hline & $\mathrm{PO}$ & LTFA & & & \\
\hline Recovery & $59.2(45 / 76)$ & $50.0(39 / 78)$ & 0.7 & $0.3-1.3$ & 0.24 \\
\hline \multicolumn{6}{|l|}{ Embryo-oocyte } \\
\hline Fertilization & $73.3(33 / 45)$ & $87.2(34 / 39)$ & 2.5 & $0.9-7.8$ & 0.10 \\
\hline Grades 1 and 2 & $37.8(17 / 45)$ & $64.1(25 / 39)$ & 3.2 & $1.2-8.3$ & 0.02 \\
\hline Degenerated & $15.6(7 / 45)$ & $12.8(5 / 39)$ & 0.9 & $0.2-3.3$ & 0.52 \\
\hline Degenerated, unfertilized & $42.2(19 / 45)$ & $25.6(10 / 39)$ & 0.4 & $0.1-1.1$ & 0.10 \\
\hline \multicolumn{6}{|l|}{ Embryos } \\
\hline Grades 1 and 2 & $51.5(17 / 33)$ & $73.5(25 / 34)$ & 3.1 & $1.0-9.2$ & 0.05 \\
\hline Degenerated & $21.2(7 / 33)$ & $14.7(5 / 34)$ & 1.6 & $0.4-5.5$ & 0.85 \\
\hline \multicolumn{6}{|l|}{ Blastomeres } \\
\hline Mean \pm SEM & $19.4 \pm 0.7$ & $22.0 \pm 0.7$ & - & - & 0.01 \\
\hline Median, n & 19 & 21 & - & - & 0.23 \\
\hline Live, $\%$ & $86.9 \pm 4.2$ & $95.3 \pm 4.2$ & - & - & 0.15 \\
\hline \multicolumn{6}{|l|}{ Acessory spermatozoa, $n$} \\
\hline Mean \pm SEM & 21.1 & 33.3 & - & - & 0.001 \\
\hline Median & 8.0 & 15.0 & - & - & 0.19 \\
\hline Embryo-oocyte $\geq 1$ & $82.2(37 / 45)$ & $89.7(35 / 39)$ & 1.9 & $0.5-6.8$ & 0.33 \\
\hline
\end{tabular}

${ }^{1} \mathrm{PO}=$ calcium salt of palm oil LTFA $=$ calcium salt of linoleic and trans-octadecenoic acids.

${ }^{2} \mathrm{AOR}=$ adjusted odds ratio. The PO treatment was used as the referent group.

${ }^{3} \mathrm{CI}=$ confidence interval. 
correlations between plasma metabolites and embryooocyte responses (fertilization, grade quality, number of blastomeres, percentage of live blastomeres, and accessory spermatozoa) had a correlation coefficient of $\leq 0.3$ and they were all nonsignificant $(P>0.10)$. Average concentrations of NEFA during the postpartum period did not differ $(P=0.68)$ between cows with or without embryos graded as 1 and 2, and they were, respectively, $0.73 \pm 0.05$ and $0.76 \pm 0.06 \mathrm{mEq} / \mathrm{L}$. Similarly, mean BHBA concentrations during the postpartum period were, respectively, $1,378.9 \pm 120.8$ and $1,150.0 \pm 144.1$ $\mu \mathrm{mol} / \mathrm{L}$ for cows with or without embryos graded 1 and $2(P=0.22)$. Even when peak concentrations of NEFA or BHBA during the postpartum period were analyzed in place of mean concentrations, no significant differences were observed between cows with or without embryos graded 1 and 2, and they were, respectively, $1.04 \pm 0.07$ and $1.14 \pm 0.09 \mathrm{mEq} / \mathrm{L}$ of NEFA $(P=$ $0.38)$, and $2,354.2 \pm 214.7$ and $1,786.0 \pm 256.1 \mu \mathrm{mol} / \mathrm{L}$ of BHBA $(P=0.12)$.

\section{DISCUSSION}

Improvements in fertilization and early embryonic development were observed in embryos-oocytes collected from cows fed a diet enriched with LTFA. Embryos-oocytes from cows fed LTFA had an increased proportion of fertilized oocytes and mean number of accessory spermatozoa. Furthermore, the proportion of embryos-oocytes or only embryos graded as 1 and 2 were greater when cows were fed LTFA than when cows were fed PO. Diets were offered throughout the transition period up to 70 DIM, which is probably the most appropriate time to positively affect the overall metabolic status and the reestablishment of reproductive functions in the cow.

Concentrations of NEFA and BHBA in plasma increased, whereas that of glucose decreased abruptly immediately after calving, in a pattern already expected for a cow during the transition period (Grummer, 1995). In the present study, however, no differences were found in concentrations of NEFA, BHBA, and glucose between treatments during the transition period. These results are not in accordance with our initial hypothesis, although Juchem et al. (2004) also observed a lack of differences in metabolic responses in cows fed diets containing LTFA and PO during the transition period. Furthermore, no difference in BCS was detected throughout the experimental period, which reinforces the absence of a major alteration in the pattern of body fat mobilization. Milk fat synthesis decreased in cows supplemented with LTFA because of a reduction in milk fat content, which resulted in reduced yields of milk fat and 3.5\% FCM. These results have been observed by others who fed lactating dairy cows transoctadecenoic FA (Juchem et al., 2004; Piperova et al., 2004). The decrease in milk energy output caused by the suppressed mammary lipogenesis was probably not sufficient to promote a significant decrease in body fat mobilization, as observed by the similar concentrations of NEFA, BHBA, and glucose, and the BCS between the 2 treatments.

Previous studies reported deleterious effects of NEFA in the follicular fluid on oocyte competence (Leroy et al., 2005) and of high BHBA concentrations from 3 wk prepartum to 9 wk postpartum on the interval to pregnancy (Walsh et al., 2007). However, the indicators of metabolic status of dairy cows during the transition period were not correlated with fertilization and embryo quality in the present study. In the current study, NEFA, BHBA, and glucose were measured during the transition period, but not when embryos-oocytes were collected. Thus, metabolic changes during the transition period may not be good predictors to assess the effects of nutrient needs for lactation on early embryo development. In addition, it is possible that the effects of lactation and energetic status of the cows might influence fertility in stages after the period of early embryonic development.

The difference in proportion of cyclic cows between treatments was not expected because measures of energy status were mostly similar. Juchem et al. (2008) observed no effect of fat sources differing in FA profile on the interval to first postpartum ovulation or proportion of cows cyclic at 6 wk postpartum. Similarly, Santos et al. (2008b) indicated that fat feeding, but not type of FA, affected the resumption of postpartum ovulation in lactating dairy cows. The responses to hormonal treatments during synchronization of ovulation, ovulatory follicle and CL diameters, and concentrations of progesterone in plasma were all similar for cows fed PO and those fed LTFA. Previous studies, however, showed positive effects of supplementation with linoleic and $\alpha$-linolenic acids on preovulatory follicle diameter and CL volume on d 7 after AI (Bilby et al., 2006) and on progesterone concentration from d 6 to 8 after ovulation (Thangavelu et al., 2007) in lactating cows. Increased preovulatory follicle diameter is expected to result in a larger CL, which explains the findings by Bilby et al. (2006). Although fat feeding clearly affects follicle diameter (Santos et al., 2008b), it is less clear whether the type of FA has a differential effect on this response. The effect of polyunsaturated FA on steroidogenesis (Wathes et al., 2007), particularly affecting the regulation of the steroid acute regulatory protein, could partially explain the improvements in CL function in previous studies. Differences in responses between the current study and the findings by others may be attrib- 
uted to when progesterone was measured. It is possible that dietary effects on CL function are not observed during metestrus and early diestrus. In addition, the amounts of polyunsaturated FA fed by others (Bilby et al., 2006; Thangavelu et al., 2007) were substantially greater than those used in the current study, and one cannot reject the view that the response to FA is dose dependent. The optimal level for supplementation of specific FA such as LTFA in the diet of dairy cows to improve fertility is unknown (Juchem et al., 2008; Santos et al., 2008b), and a major impediment is the lack of an accurate prediction of specific FA flow to the small intestine available for absorption (Santos et al., 2008b).

Cows were flushed $5 \mathrm{~d}$ after AI, and recovery rate averaged $54.5 \%$ for both treatments. Other studies that attempted to recover embryos-oocytes from nonsuperovulated cows at a similar interval from induction of ovulation had a similar recovery rate (Villaseñor et al., 2008; Cerri et al., 2009a,b). The reason for the relatively low recovery is still unclear. A possibility is that a residual embryo-oocyte is still in the oviduct on $\mathrm{d} 5$ after the induction of ovulation. Embryos-oocytes from cows fed LTFA had a greater mean number of accessory spermatozoa and increased fertilization compared with cows fed PO. It is possible that the increased number of spermatozoa reaching the oviduct might improve the fertilization of oocytes. Cerri et al. (2009b) observed that the number of accessory spermatozoa that resulted in the best sensitivity and specificity for fertilization was 4 , and cows with embryos-oocytes containing $\geq 7$ accessory spermatozoa had $100 \%$ fertilization. Furthermore, feeding the same types of supplemental FA used in the current study reduced the incidence of more severe metritis in dairy cows in the first 2 wk postpartum (Juchem et al., 2008). Clinical uterine diseases postpartum are known to increase the risk of subclinical endometritis in lactating dairy cows (Rutigliano et al., 2008), and the latter suppresses fertility (Rutigliano et al., 2008), partly because of reduced fertilization rate (Cerri et al., 2009a). Subclinical endometritis was not evaluated in the current study, but it is possible that feeding LTFA changed uterine health or increased the concentration of unsaturated FA in endometrial cell phospholipids (Wathes et al., 2007), which might have favored sperm transport to the site of fertilization.

Juchem et al. (2008) observed that cows fed LTFA had a small increase in plasma concentrations of $\mathrm{PGF}_{2 \alpha}$ metabolite in the first $2 \mathrm{~d}$ postpartum and a reduced incidence of acute puerperal metritis compared with cows fed PO, although the incidence of retained placenta and the overall incidence of metritis were unaltered. Nevertheless, pregnancy to first postpartum AI was increased by feeding LTFA. It is possible that improve- ments in fertilization were the result of improved uterine health (Cerri et al., 2009a), which subsequently led to increased pregnancy per AI (Juchem et al., 2008). In addition, the effects of LTFA on the cellular and molecular pathways involved in the fertilization process in the cow are largely unknown. This possibility cannot be rejected because these FA can function as signaling molecules and affect cell membrane properties (Wathes et al., 2007).

The present study initially hypothesized that the beneficial effect on pregnancy observed by Juchem et al. (2008) could be caused by improved fertilization and embryo quality. Cows fed LTFA indeed had improved fertilization and yielded a greater proportion of grades 1 and 2 embryos, and their embryos had more blastomeres. Improvements observed in pregnancy in lactating dairy cows fed LTFA might, in part, be attributed to better embryo quality. There are no detailed descriptions of FA content in bovine embryos from fertilization to $\mathrm{d} 5$ of development, but there is a clear tendency toward the uptake of unsaturated FA by embryos as they develop from d 7 to 14 after AI (Menezo et al., 1982). For instance, the content of linoleic acid increased from 0.5 to $5.7 \%$ of the total FA content of the embryo from d 7 to 13, suggesting increased uptake of linoleic acid as the embryo grows. Haggarty et al. (2006) observed an increase in the incorporation of linoleic acid in cultured human embryos that developed beyond the 4-cell stage compared with embryos that did not reached the 4-cell stage. Moreover, an increase in the number of blastomeres was detected in embryos collected on $\mathrm{d} 7$ after AI in superovulated cows treated with diets containing more linoleic or $\alpha$-linolenic acids compared with a diet containing more saturated FA (Thangavelu et al., 2007).

Oocyte competence also seems to be affected by dietary supplemental fat in dairy cows. Increasing the amount of dietary fat increased the number of trophectoderm cells from in vitro-produced blastocysts originating from oocytes of cows fed a diet with increased fat content from calcium salts of PO (Fouladi-Nashta et al., 2007). In fact, fat feeding has generally improved embryo quality in embryo donor cows (Santos et al., 2008a). Interestingly, oocytes and the surrounding cells had a 3 - to 4 -fold increase in the concentrations of linoleic acid when derived from cows in the winter months compared with the summer months (Zeron et al., 2001). Such changes in oocyte membrane composition may contribute to the increased fertility of dairy cows in the winter months compared with the summer months (Zeron et al., 2001). Linoleic acid also has been implicated in the regulation of meiotic arrest in bovine oocytes at the germinal vesicle stage, because Homa and Brown (1992) showed a negative correlation 
between diameter of the follicle and content of linoleic acid in the follicular fluid. Despite indications that unsaturated FA have differential effects on the oocyte (Wathes et al., 2007; Santos et al., 2008a), models in vitro have not supported these suggestions. Bilby et al. (2006) observed no effect on in vitro oocyte nuclear maturation and apoptosis when cows were fed supplemental FA with different degrees of unsaturation or on in vitro embryonic development. Differences between the findings of the current study and those of Bilby et al. (2006) suggest either that an in vitro system may not reflect in vivo findings (Santos et al., 2008a), or that beneficial effects observed in the current study and in others (Juchem et al., 2008) may be related to factors other than oocyte competence. Potential biological windows are the oviduct and the uterine environment.

\section{CONCLUSIONS}

Results from the current study demonstrate a differential effect of type of FA on fertilization and embryo quality in nonsuperstimulated lactating dairy cows. Feeding calcium salts of LTFA from late gestation to 70 d postpartum improved fertilization and embryo quality. Improvements in fertilization and embryo quality were not associated with responses of energy status, and indicators of metabolic status were not affected by the different fat sources. Milk fat synthesis clearly decreased in cows fed LTFA, but this was insufficient to promote changes in body fat mobilization. The beneficial effect observed in fertilization and embryo quality in cows fed LTFA probably was associated with an increased availability of LTFA to the uterus, the oocyte, and the embryo. Further studies, however, should be conducted to isolate the actions of each FA on the reproduction of dairy cows. In addition, the cellular and molecular pathways that led to improvements in fertilization and embryo quality remain to be elucidated.

\section{ACKNOWLEDGMENTS}

This research was supported by grants from the National Research Initiative USDA Research Grant no. 2004-35203-14137 from the USDA (Washington, DC), USDA formula funds, and the Center for Food Animal Health of the University of California-Davis. The authors thank Virtus Nutrition (Fairlawn, OH) for partial funding and also for provision of the calcium salts used in this study; Pfizer Animal Health (New York, NY) for the donation of $\mathrm{PGF}_{2 \alpha}$; and Merial Ltd. (Iselin, NJ) for the donation of GnRH. Our gratitude is also extended to Oscar Rodriguez and the farm staff for use of their animals and facilities.

\section{REFERENCES}

Bilby, T. R., J. Block, B. C. do Amaral, O. Sá Filho, F. T. Silvestre, P. J. Hansen, C. R. Staples, and W. W. Thatcher. 2006. Effects of dietary unsaturated fatty acids on oocyte quality and follicular development in lactating dairy cows in summer. J. Dairy Sci. 89:3891-3903

Burr, G. O., and M. M. Burr. 1930. On the nature and role of the fatty acids essential in nutrition. J. Biol. Chem. 86:587-621.

Castañeda-Gutiérrez, E., B. C. Benefield, M. J. de Veth, N. R. Santos, R. O. Gilbert, W. R. Butler, and D. E. Bauman. 2007. Evaluation of the mechanism of action of conjugated linoleic acid isomers on reproduction in dairy cows. J. Dairy Sci. 90:4253-4264.

Cerri, R. L. A., H. M. Rutigliano, R. C. Chebel, and J. E. P. Santos. 2009b. Period of dominance of the ovulatory follicle influences embryo quality in lactating dairy cows. Reproduction (accepted).

Cerri, R. L. A., H. M. Rutigliano, F. S. Lima, D. B. Araujo, and J. E. P. Santos. 2009a. Effect of source of supplemental selenium on uterine health and embryo quality in high-producing dairy cows. Theriogenology doi:10.1016/j.theriogenology.2008.12.005

Cerri, R. L. A., J. E. P. Santos, S. O. Juchem, K. N. Galvão, and R. C. Chebel. 2004. Timed artificial insemination with estradiol cypionate or insemination at estrus in high-producing dairy cows. J. Dairy Sci. 87:3704-3715.

DePeters, E. J., J. B. German, S. J. Taylor, S. T. Essex, and H. PerezMonti. 2001. Fatty acid and triglyceride composition of milk fat from lactating Holstein cows in response to supplemental canola oil. J. Dairy Sci. 84:929-936.

Ferguson, J. D., D. T. Galligan, and N. Thomsen. 1994. Principal descriptors of body condition score in Holstein cows. J. Dairy Sci. 77:2695-2703.

Fouladi-Nashta, A. A., C. G. Gutierrez, J. G. Gong, P. C. Garnsworthy, and R. Webb. 2007. Impact of dietary fatty acids on oocyte quality and development in lactating dairy cows. Biol. Reprod. 77:9-17.

Grummer, R. R. 1995. Impact of changes in organic nutrient metabolism on feeding the transition dairy cow. J. Anim. Sci. 73:2820-2833.

Haggarty, P., M. Wood, E. Ferguson, G. Hoad, A. Srikantharajah, E. Milne, M. Hamilton, and S. Bhattacharya. 2006. Fatty acid metabolism in human preimplantation embryos. Hum. Reprod. 21:766-773.

Homa, S. T., and C. A. Brown. 1992. Changes in linoleic acid during follicular development and inhibition of spontaneous breakdown of germinal vesicles in cumulus-free bovine oocytes. J. Reprod. Fertil. 94:153-160.

International Embryo Transfer Society. 1998. Manual of the International Embryo Transfer Society. 3rd rev. ed. Int. Embryo Transfer Soc., Savoy, IL.

Juchem, S. O., R. L. A. Cerri, M. Villaseñor, K. N. Galvão, R. G. S. Bruno, H. M. Rutigliano, E. J. DePeters, F. T. Silvestre, W. W. Thatcher, and J. E. P. Santos. 2008. Supplementation with calcium salts of linoleic and trans-octadecenoic acids improves fertility of lactating dairy cows. Reprod. Domest. Anim. doi:10.1111/j.14390531.2008.01237.x

Juchem, S. O., R. L. A. Cerri, M. Villasenor, K. N. Galvão, R. G. S. Bruno, H. M. Rutigliano, A. C. Coscioni, E. J. DePeters, W. W. Thatcher, D. Luchini, and J. E. P. Santos. 2004. Effect of feeding calcium salts of palm oil (PO) or of a blend of linoleic and monoenoic trans-fatty acids (LTFA) on lactation and health of lactation Holstein cows. J. Dairy Sci. 87(Suppl. 1):95. (Abstr.)

Kindahl, H., K. Odensvik, S. Aiumlamai, and G. Fredriksson. 1992. Utero-ovarian relationship during the bovine post-partum period. Anim. Reprod. Sci. 28:363-369.

Leroy, J. L. M., T. Vanholder, B. Mateusen, A. Christophe, G. Opsomer, A. Kruif, G. Genicot, and A. V. Soom. 2005. Nonesterified fatty acids in follicular fluid of dairy cows and their effect on developmental capacity of bovine oocytes in vitro. Reproduction 130:485-495.

Mattos, R., A. Guzeloglu, L. Badinga, C. R. Staples, and W. W. Thatcher. 2003. Polyunsaturated fatty acids and bovine interferon- $\tau$ modify phorbol ester-induced secretion of prostaglandin $F_{2 \alpha}$ 
and expression of prostaglandin endoperoxide synthase- 2 and phospholipase- $\mathrm{A}_{2}$ in bovine endometrial cells. Biol. Reprod. 69:780-787.

Mattos, R., C. R. Staples, A. Arteche, M. C. Wiltbank, F. J. Diaz, T. C. Jenkins, and W. W. Thatcher. 2004. The effects of feeding fish oil on uterine secretion of $\mathrm{PGF}_{2 \alpha}$, milk composition, and metabolic status of periparturient Holstein cows. J. Dairy Sci. 87:921-932.

Menezo, Y., J. Renard, B. Delobel, and J. Pageaux. 1982. Kinetic study of fatty acid composition of day 7 to day 14 cow embryos. Biol. Reprod. 26:787-790.

NRC. 2001. Nutrient Requirements of Dairy Cattle. 7th rev. ed. Natl. Acad. Press, Washington, DC.

Piperova, L. S., U. Moallem, B. B. Teter, J. Sampugna, M. P. Yurawecz, K. M. Morehouse, D. Luchini, and R. A. Erdman. 2004. Changes in milk fat in response to dietary supplementation with calcium salts of trans-18:1 or conjugated linoleic fatty acids in lactating dairy cows. J. Dairy Sci. 87:3836-3844.

Pursley, J. R., M. O. Mee, and M. C. Wiltbank. 1995. Synchronization of ovulation in dairy cows using $\mathrm{PGF}_{2 \alpha}$ and $\mathrm{GnRH}$. Theriogenology 44:915-923.

Rutigliano, H. M., F. S. Lima, R. L. A. Cerri, L. F. Greco, J. M. Vilela, V. Magalhães, F. T. Silvestre, W. W. Thatcher, and J. E. P. Santos. 2008. Effects of method of presynchronization and source of selenium on uterine health and reproduction in dairy cows. J. Dairy Sci. 91:3323-3336.

Santos, J. E. P., T. R. Bilby, W. W. Thatcher, C. R. Staples, and F. T. Silvestre. 2008b. Long chain fatty acids of diet as factors influencing reproduction in cattle. Reprod. Domest. Anim. 43(Suppl. 2):23-30.

Santos, J. E. P., R. L. A. Cerri, and R. Sartori. 2008a. Nutritional management of the donor cow. Theriogenology 69:88-97.

Staples, C. R., J. M. Burke, and W. W. Thatcher. 1998. Influence of supplemental fats on reproductive tissues and performance of lactating cows. J. Dairy Sci. 81:856-871.

Thangavelu, G., M. G. Colazo, D. J. Ambrose, M. Oba, E. K. Okine, and M. K. Dyck. 2007. Diets enriched in unsaturated fatty acids enhance early embryonic development in lactating Holstein cows. Theriogenology 68:949-957.

Villaseñor, M., A. C. Coscioni, K. N. Galvão, R. C. Chebel, and J. E. P. Santos. 2008. Gossypol disrupts embryo development in heifers. J. Dairy Sci. 91:3015-3024.

Walsh, R. B., J. S. Walton, D. F. Kelton, S. J. LeBlanc, K. E. Leslie, and T. F. Duffield. 2007. The effect of subclinical ketosis in early lactation on reproductive performance of postpartum dairy cows. J. Dairy Sci. 90:2788-2796.

Wathes, D. C., D. R. E. Abayasekara, and R. J. Aitken. 2007. Polyunsaturated fatty acids in male and female reproduction. Biol. Reprod. 77:190-201.

Zeron, Y., A. Ocheretny, O. Kedar, A. Borochov, D. Sklan, and A. Arav. 2001. Seasonal changes in bovine fertility: Relation to developmental competence of oocytes, membrane properties and fatty acid composition of follicles. Reproduction 121:447-454. 